\title{
Developing a Personalised Learning Model Based on Interactive Novels to Improve the Quality of Mathematics Education
}

\author{
Elena V. Soboleva ${ }^{1 *}$ (D), Khurshidzhon K. Zhumakulov ${ }^{2}$ (D), Kayumzhon P. Umurkulov ${ }^{2}$ (D), \\ Gasanguseyn I. Ibragimov ${ }^{3}$ (D), Lyubov V. Kochneva ${ }^{4}$ (D), Maria O. Timofeeva ${ }^{5}$ (D) \\ ${ }^{1}$ Vyatka State University, Kirov, RUSSIA \\ ${ }^{2}$ Kokand State Pedagogical Institute named after Mukimi, Kokand, UZBEKISTAN \\ ${ }^{3}$ Kazan (Volga region) Federal University, Kazan, RUSSIA \\ ${ }^{4}$ Moscow Aviation Institute (National Research University), Moscow, RUSSIA \\ ${ }^{5}$ I.M. Sechenov First Moscow State Medical University (Sechenov University), Moscow, RUSSIA
}

Received 12 December 2021 - Accepted 19 January 2021

\begin{abstract}
The lack of sufficiently developed methodological basis before graduation adversely affects the mathematical competency of future experts that are required by the modern economy. The study aims to investigate the features of the development of a personalized model of teaching mathematics by means of interactive novels to improve the quality of educational results. The main methods of research were the generalization of pedagogical experience and science literature, modelling, observation, analysis of results in AXMA Story Research methods. The chosen methods made it possible to justify the necessity of using interactive novels to personalize teaching mathematics and to confirm the qualitative improvements in the pedagogical system. Fisher's criterion was used to evaluate the results. 121 schoolchildren from Russian and Uzbek schools participated in the experiment. Individual educational routes supporting the studying of mathematical theory, problem solving in the interactive space AXMA Story Maker were developed. The peculiarities to be considered when designing a personalized model of mathematics learning by means of interactive novelties were formulated. These are the correlation between the didactic goal and the result of educational and research work in a nonlinear environment, the selection of the plot for a visual novel, the elaboration of the text component and the personalized learning track, etc. According to ANCOVA test results, the post-score of the experimental group is statistically higher than the control group. The results of the article can be used to develop ideas for personalising of learning in the digital school, as well as justification for the need for inclusion of digital interactive tools in mathematics education at all levels of education and training.
\end{abstract}

Keywords: mathematics education, digital technologies, interactive environment, visual short story, personalization of learning, AXMA Story Maker

\section{INTRODUCTION}

\section{The Relevance of the Problem}

The implementation of educational programs in modern schools, including in mathematics, involves taking into account the principles of personalized learning, the active use of digital technologies, means of interactive interaction to ensure a high level of mathematical education (Insorio \& Librada, 2021; Karakozov \& Ryzhova, 2019).

The study and analysis of the results of educational activities allow us to obtain important information about the quality of school-leavers' training.

However, the assessment of the mathematical education results is particularly difficult. Kotyurgina et al. (2020) notes: “... the most important results of education are not passing the Unified State Exam and

(c) 2022 by the authors; licensee Modestum. This article is an open access article distributed under the terms and conditions of the Creative Commons Attribution License (http://creativecommons.org/licenses/by/4.0/). 


\section{Contribution to the literature}

- The study aims to investigate the features of the development of a personalized model of teaching mathematics by means of interactive novels to improve the quality of educational results

- The features that should be taken into account when designing a personalised model of teaching mathematics by means of interactive novels are revealed.

- The results of the article can be used to develop ideas for personalising of learning in the digital school, as well as justification for the need for inclusion of digital interactive tools in mathematics education at all levels of education and training.

State Final Examination, but multisubject and personal results formulated in the new standards".

The key importance in achieving personal results, which is confirmed by the provisions of the Industry 4.0, is given to the study of an algebra, geometry.

Mathematics education is an integral part of general education. Mathematics is one of the basic subjects at school, it supports the study of other disciplines (physics and mathematics, humanitarian, etc.). In modern conditions a certain amount of fundamental mathematics knowledge, knowledge of mathematics methods are becoming compulsory elements of the culture of the nation. In addition, learning mathematics performs developmental functions: intellectual skills, which are necessary for any person, regardless of what field of the activity the person will be engaged in the future, are formed.

In the theory and methodology of teaching mathematics, according to Perminov et al. (2019), much attention is paid to the search and implementation of new methods and means for high-quality training of graduates of secondary schools to consciously use mathematics knowledge and skills necessary for their future professional activities, and the formation of holistic ideas about this science as part of the common human culture.

Modern education analysts at the Higher School of Economics under the leadership of Lyubimov (2020) are developing the author's Concept for the Modernization of Education and believe that the new society needs people who can independently make decisions, ... predict their possible consequences" (Lyubimov, 2020). The inclusion of interactive digital means in the educational, cognitive, mathematics activities of students should contribute not only to increasing academic performance in mathematics, but also to contribute to the holistic development of the personality, the realization of creative abilities and cognitive interests of each student (Galimova et al., 2019). The effectiveness of the organization of the corresponding mathematical activity, according to the conclusions of Alfaro-Arce and Alpízar-Vargas (2019), is determined by the capabilities and skills of a mentor in a digital school.

In other words, innovative pedagogical technologies and modern digital re-sources should be the basis of the information educational environment that takes into account individual personality traits. Isupova and Suvorova (2018) argue that in the modern personified educational space, digital resources should complement and expand the range of educational and cognitive influences, enrich cognitive practice, and promote the mastery of the culture of thinking.

Such thinking, according to Novitasari et al. (2020), is most in demand in the modern society (science, industry and economics), since the corresponding intellectual activity supports decision-making in an uncertain future. The visual component of interactive media affects visual and emotional memory (Olefirenko et al., 2019).

Thus, there is a practical need for the use of interactive digital tools to improve the quality of teaching mathematics in the personified educational space.

A visual novel is the means of interactive learning. It represents history. The artistic image and content of the novel may vary depending on the actions of the student. The use of software services for the implementation of interactive novels contributes to the formation of students' thinking, involving the search for different ways to achieve the goal, understanding the laws of randomness.

Such thinking, according to Novitasari et al. (2020), is most in demand in the modern society (science, industry and economics), since the corresponding intellectual activity supports decision-making in an uncertain future. Thus, there is a practical need for the use of interactive digital tools to im-prove the quality of teaching mathematics in the personified educational space.

\section{Goals and Tasks of the Research}

The purpose of the study is determined from the need to study the features of the development of a personalized model of teaching mathematics by means of interactive novels to improve the quality of mathematics education.

The following were identified as the main objectives:

- to clarify the essence of the concepts: "personalization of learning", "personalized learning model", "visual interactive novel" in the context of the requirements of the digital school; 
- to describe the didactic potential of AXMA Story Maker as a visual interactive novel development tool;

- to design a personalized environment for teaching mathematics based on interactive novels, focused on improving the quality of educational results of schoolchildren;

- to describe the directions of the cognitive activity of schoolchildren in the AXMA Story Maker environment;

- to present the system of the teacher's work on the structure of the visual interactive novel, its text (task) component;

- to experimentally test the effectiveness of the developed teaching methodology by means of interactive novels to improve the quality of mathematics education of specialists of the future.

\section{LITERATURE REVIEW}

\section{Analysis of Russian Scientific and Pedagogical Literature}

To confirm the objective need to improve the quality of mathematical training of graduates by means of interactive novels, fundamental scientific works devoted to identifying the essence of the concept of "interactive novel" and describing the didactic potential of digital services in terms of supporting personalised learning were analyzed.

The inclusion of interactive novels and educational quests in the cognitive activity of students are current directions for the development of the didactic system (Karavaev \& Soboleva, 2017). Perminov et al. (2019) also conclude that in the general system of knowledge there is an increase in the importance of mathematics, the penetration of mathematics models and methods into various spheres of human life (Perminov et al., 2019).

Varshavskaya and Kotyrlo (2019) notes that global digital transformation has a significant impact on the demands of society, business, and the state regarding professions in demand in the future. However, in practice, schools and universities often prepare graduates without taking into account trends in longterm planning, competitiveness, uncertainty of the future (Perminov et al., 2019; Qarkaxhja et al., 2021; Shaidullina et al., 2018). A significant role is assigned to motivational, psychological, socio-economic, technical conditions for supporting the self-determination of a future specialist (Varshavskaya \& Kotyrlo, 2019). The personality of the teacher, his understanding and ability to design a digital educational space that meets the challenges of global transformation must remain consistently leading.

It is the mentor of the digital school who can and should choose personalized learning technologies that maximally work to form the type of thinking and way of action that is in demand in the digital society.

In these conditions in the theory and methodology of teaching mathematics it is necessary to pay more attention to preparing graduates of a general education school for the use of mathematics knowledge and skills which are necessary for their future professional activities and the formation of ideas about this science as part of a common human culture.

Research by Solodykhina and Solodykhina proves that the greatest demand in the era of digital transformation will be used by specialists with planning skills in the conditions of the future, the ability to formulate a problem independently. They should be ready to offer the optimal solution, be able to develop a solution algorithm and implement it by software and hardware (Ponomarev \& Dezhina, 2016; Solodikhina \& Solodikhina, 2019). Soboleva et al. (2020) clarifies that the professional of the future should also be able to shift the existing solution of the problem to a possible one in the future.

Urvanova (2018) notes that high-quality teaching mathematics in the digital school presupposes the active inclusion of interactive digital means in educational and cognitive activities of students.

Their choice and application should contribute to increasing academic performance in mathematics, the realization of the creative abilities and cognitive interests of each student.

This position confirms the theory that digital literacy of a modern person necessarily includes a communicative component (Alexandrov et al., 2017). Semenykhina and Rudenko (2018) explores experiment and information interaction in the development of mobile applications, gaming educational spaces. Other authors complement these ideas and argue that distant technologies, e-learning, interactive tools and activity methods should be used when teaching mathematics (Galimova et al., 2019).

Urvanova (2018) also formulates the condition that innovative pedagogical technologies and modern digital resources should be the basis of the educational environment, adjusted to individual personality traits. Moreover, Urvanova (2018) notes that in such a specially designed educational model the student receives maximum conditions for the development of "the ability to learn".

Researches on the study of the issues of personalization of learning and the use of digital technologies to design a personalized learning model were also analyzed.

For example, Chernyaeva (2020) reasonably argues that an important direction in the educational policy is the transition from "mass" education to the personalized one. According to the author, the main aim of personalized learning is to provide conditions for self- 
realization of students. Savina (2020) notes that in the personalized educational model the student receives maximum conditions for the development of "the ability to learn". Appropriate conditions must be supported by the personal educational route, a trajectory of cognition, curriculum, and information environment.

The most comprehensive methodological approach to developing the personalized model of teaching mathematics based on digital technologies is presented in the study of Sabirova et al. (2019). The authors conclude that the number of digital educational resources for personalization of learning is constantly increasing. However, in order to purposefully and methodologically effectively include the appropriate services in the educational process the mentor needs to know principles and conditions of personalization of education. In addition, it is the teacher who should understand the range of educational tasks that can be solved with the help of electronic resources; determine methodological functions, types of educational activities that digital technologies support and initiate. The purpose of their research is to identify the effectiveness of the interactive educational platform Uchi.ru for personalized teaching of mathematics in primary school.

So, there is an objective need to analyze and generalize the experience of using modern interactive methods and tools when teaching mathematics.

Vaganova et al. (2020) examine the general methodological aspects of organizing the learning process using modern interactive didactic tools. In the research the concept of "interactivity" refers to the interaction between objects. The authors formulate the following requirements for interactive teaching aids: support of motivation (the appearance of an incentive for students to study the subject); management and regulation (directing the attention of students to the study of objects, phenomena). Isaeva (2019) notes the following didactic properties of interactive teaching tools: multimedia, instrumentality, adaptability, information content, motivation. Soboleva and Perevozchikova (2019) prove that designing interactive quest rooms as organizational forms of cognition and educational technology is not one of the options for gamification of the digital educational space, but also contributes to the formation of intellectual competence of the individual. In the job of Karavaeva and Soboleva (2017), various gaming services and platforms with didactic potential in terms of the development of relevant skills and abilities are analyzed.

Nikolaeva and Egorova (2020) prove that with the help of interactive methods it is possible to increase academic performance in the subject, the involvement of student's activities, thereby contributing to the personalization of learning. Including interactive techniques has a beneficial effect on creative, critical and creative thinking.
Levchenko and Mantorova (2020) describe the concept of a visual interactive novel "Getting Through" as a variant of the development of creative thinking, imagination and formation of foundations of the scientific worldview. However, such interactive tools have been developed only for classes in history, literature, and English.

Thus, Russian modern researchers convincingly prove that the inclusion of interactive services for visual novels and quests in educational and cognitive activities not only meet the goals and challenges of the education system (Smirnov et al., 2019), but also allows to prepare demanded and competitive professionals of the future for the country's economy.

\section{Analysis of Foreign Studies}

Analytical work in this part of the study was also carried out in three directions: search for new methods and means in teaching mathematics to improve the quality of mathematics education; identifying the didactic potential of digital technologies to support the personalization of teaching mathematics; generalization of the experience of using modern interactive methods and tools when teaching mathematics.

As part of the first direction, it should be noted that foreign scientists are unanimous in the opinion that it is educational achievements in mathematics that are the basis of quality education in general (del Río et al., 2019; Gault, 2019). In particular, Park et al. (2016) reasonably argue that mathematics knowledge acquired in primary school determines the success of further education, readiness of adolescents to think independently, and to the reasoned activity. Researchers identify five conditions for personalized learning: formation of subject-oriented skills; development of thinking (critical, analytical); support of students by the teacher; use of various didactic methods, forms and means of teaching (for example, electronic educational resources, simulators, educational and interactive quests); use of information technologies when teaching (Hamada \& Hasan, 2017).

According to Bawa et al. (2020), development of personalized learning is one of the priorities of modern mathematics education. The authors conclude that the use of information technologies can improve the quality of teaching mathematics. Authors study the didactic potential of multimedia programs (combining text, sound and music, graphics, animation and still images) in teaching elementary mathematics. Based on statistical data they substantiate the effectiveness of such multimedia applications for the development of mathematics skills. Hillmayr et al. (2020) also conclude that the use of digital technologies can improve the quality of teaching mathematics. At the same time, scientists carry out the experiment which confirms that the use of intelligent learning systems, modeling and 
work with dynamic mathematical tools is much more effective than the usual multimedia course support.

Bovermann and Bastiaens (2020) conclude that the use of interactive tools and applications in the mathematics classroom provides variability in the presentation of tasks, uniqueness of exercises, quick assessment, and necessary trajectory correction, changes in the difficulty of the level, competitiveness and the game approach to learning. To create such applications tools that are part of the integrated Microsoft Office suite and other applications that do not require programming skills are used (Bovermann \& Bastiaens, 2020).

In turn, an increase in literacy, formation of the critical worldview is the basis for the preparation of future generations (Radović et al., 2019).

Scientists note that in modern mathematical education, attention is increasing to language as a tool for expressing thought, which has unique cognitive capabilities. The continuation of these ideas can be seen in modern scientific works (More, 2018; Paterson, 2017). Through language, a person combines in consciousness the information received during spatial perception and mathematical activity (Záhorec et al., 2010). Spatial cognition provides information about the location of an object and information about its properties, such as color or size, for reflection. Mathematical cognition operates with numbers. Only language makes it possible to integrate these contents into a single whole - cognized (Zaripova et al., 2014; Zeynivandnezhad \& Bates, 2018).

According to the provisions of J.F. Harding et al. personalization is the creation of the learning environment which matches unique abilities and needs of the student in order to achieve the potential of students (qualities, talents). Personalization is a process during which the subject acquires individual properties and qualities that allow him / her to fulfill a certain social role, to build relationships with other people (Catarino et al., 2019).

The concept of "personalized learning" is used to refer to a process that consists of a set of educational programs, methods and teaching techniques, which is aimed at identifying and taking into account educational needs, interests and individual characteristics of the student (Radović et al., 2019). Improving the quality of mathematical education in the context of personalisation involves an innovative approach to learning, the use of non-standard tools and technologies (Catarino et al., 2019). The technology of educational quests can be one of these. A number of papers present the inclusion of game elements in arithmetic activities (Legaki et al., 2020).

According to Ghazali et al. (2019), education in school should take into account cognitive interests and professional aspirations of the student. In the work of Yung et al. (2020), based on the analysis and generalization of the didactic capabilities of QR codes for teaching, priorities for the development of web technologies, interactive short story services, the authors reasonably highlight a promising direction in the new educational realities - the use of game mechanics to support the cognitive activity of students in the mathematics course. The use of means of interactive novels and quests in the mathematics activity, the construction of a mathematical model in a playful form helps to activate knowledge, increase the interest and curiosity of the teenager of generation $\mathrm{Z}$. The authors note that with the help of such visual objects it is possible to increase mathematics academic progress, involvement of student's activities, thereby contributing to the personalization of learning.

Using interactive techniques stimulates creative, critical and creative thinking (Hiranyachattada \& Kusirirat, 2020; Kaya \& Adiguzel, 2021; Lai, 2019; MoraLuis \& Martin-Gutierrez, 2020).

Improving the quality of mathematics education in the context of personalization presupposes the innovative approach to teaching, the use of nonstandard tools and technologies (Catarino et al., 2019).

Moreover, if applied correctly, this approach can qualitatively increase the effectiveness mastering the educational material and activate the cognitive activity of schoolchildren, and promote professional selfdetermination (Paiva et al., 2020).

However, as the analysis of the literature has shown the practical implementation of interactive visual short stories and quests in teaching mathematics, the use of software applications that take into account the principles of didactics and contribute to improving the quality of mathematics education cause certain difficulties (More, 2018). It should be noted that there is a need to allocate additional time and labor resources, work with the educational mathematical content of the application, knowledge of the basics of didactics and their use in practice, the choice of software, etc.

Thus, new challenges of the time determine modernization of mathematics school education: a transition to personalized learning takes place (Bawa et al., 2020), interactive methods and means are actively used to present facts, tasks and exercises, to support modeling (Harding et al., 2019).

At the same time, in other school subjects (literature, history, English), interactive technologies also support formation of the scientific picture of the world, development of mental processes, and creativity. In particular, game applications and visual interactive novels are being developed. Therefore, to improve the quality of teaching mathematics it seems appropriate to use such interactive novels as the basis of the personalized educational environment. 


\section{MATERIALS AND METHODS}

\section{Theoretical and Empirical Methods}

The following methods were used in the study: theoretical analysis and generalization of scientific literature on the problems of improving the quality of mathematics education; using digital technologies to personalize learning; didactic potential of visual interactive literature as a kind of computer games.

The main methodological principle of the study is determined by the key condition for personalized learning and presupposes the freedom to choose the educational path. This principle of choice is realized in the space of the interactive novel. The interactive novel is both a learning tool and a play space. Interaction with the user in the visual interactive environment is implemented mainly with the help of textual information. The text can be accompanied by video, images, sounds.

The use of interactive novels in teaching mathematics is supported by the following system of didactic principles: accessibility, consistency, connection between theory and practice, conscious activity, individual approach, cooperation. On the other hand, teaching mathematics (the study of rigorous scientific facts, mathematical calculations, etc.) Is supported by the artistry of the text, ideas in the imagination of the userplayer, plot, and interaction of characters.

To obtain up-to-date information on qualitative changes in the educational achievements of students in mathematics the following empirical methods were used: observation, analysis of work results in the AXMA Story Maker application (choice of answer, number of attempts to find the right solution, study of theoretical material in publications, use of audio background, etc.).

The use of tools for designing visual interactive novel was carried out as part of the course "Entertaining mathematics". This course is included in extracurricular activities of personality development in secondary school № 11 in Kirov. An input control was organized to form the experimental and control group, the control included five tasks (do logical inferences, calculate a value from a ready-made mathematical expression, work with a problem formulation, draw up a mathematical formula, use information technologies to automate mathematical calculations). 121 schoolchildren of grade 7 were involved in work with interactive novels. The average age of the respondents was 13 (51\% girls and $49 \%$ boys).

Despite the fact that for the implementation of interactive novels there are many software tools (Twine, Quest, Apero, Kvester, AXMA Story Maker, etc.), the research uses the AXMA Story Maker application as a software tool. Its main advantages include the fact that using the application does not require programming skills, simplicity and convenience of the user interface, availability of ready-made templates for publications, support for various languages (Russian, English), the application provides a wide range of functionalities for designing visual travel games, interactive novels.

Statistical processing of the research results was performed using the Fisher test.

\section{The Research Base}

Approbation, generalization and implementation of research results are carried out:

- by teaching the courses "Information technologies in pedagogical activity", "IT in the processing of educational achievements and scientific research", "Technologies for creating educational programs" for training students in the field 44.04.01 Pedagogical education (Master's degree) based on materials developed by the author (Soboleva et al., 2017); the course has been taught since 2016 at the Vyatka State University, Kazan Federal University, National Research University, Sechenov University (Russia) and at the Kokand State Pedagogical Institute (Republic of Uzbekistan).

- by teaching the course "Theory and methods of teaching Informatics" for training students in the field 03.44.05 Pedagogical education (two profiles) based on materials developed by the author (Soboleva et al., 2017); the course has been taught since 2010 at the Vyatka State Humanitarian University, since 2016 - at the Vyatka State University, Kazan Federal University, National Research University, Sechenov University (Russia) and at the Kokand State Pedagogical Institute (Republic of Uzbekistan)..

- when organizing training in computer science and mathematics education in secondary school № 11 in Kirov and N 106 in Kazan.

The use of design tools for visual interactive novels was carried out as part of course "Entertaining mathematics". This course is included in extracurricular activities of personality development.

121 schoolchildren of grade 7 were involved in work with interactive novels. The average age of the respondents was 13 (51\% girls and $49 \%$ boys).

The sample was not random. To match the rules of probabilistic selection mathematics classes were conducted by the same teacher. This teacher also formulated systems of educational tasks, directed information interaction in the process of solving problems by schoolchildren in the AXMA Story Maker environment. Work with interactive applications was performed in the same classrooms, on the same hardware and software. The materials for the test were developed by the authors in accordance with the current standard of basic general education. 


\section{Research Stages}

The research was carried out in three stages.

At the preparatory stage of the experiment software that support the implementation of interactive visual novels was studied and analyzed: Twine, Quest, Apero, Kvester, AXMA Story Maker, etc. After comparing the software for the implementation of interactive novels according to the selected criteria, the application AXMA Story Maker was reasonably chosen. Next, the didactic potential of its tools for personalizing mathematics learning was explored. To assess the input conditions materials from a specially organized control event (5 tasks) were used.

For the correct solution of control tasks the student could receive the maximum of 12 points. The work was considered completed (mark "credit") if the student scored more than 7 points.

Thus, it was possible to collect data on 121 schoolchildren of whom the experimental (60 students) and control (61 students) groups were formed. The sample was not random. The average age of the respondents was 13. In the experimental group there were $51 \%$ of girls and $49 \%$ of boys.

The second stage of the study was to correlate the topics of the course "Entertaining mathematics" (elements of logic, formulas, equations, inequalities, motion problems, percentage problems, etc.) with the capabilities of the software for creating interactive novels. In particular, the system of classes was determined.

Level I. The study of theoretical material.

Level II. The study of the interface of the software environment and the rules of operation, frontal modeling of mathematical activity for solving problems in the commenting mode.

Level III. Reflection. A new part of theory.

Level IV. Participation in a visual interactive novel to consolidate the acquired mathematical skills.

Level V. Reflection. Discussion of errors and analysis of their resolution options.

Level VI. Independent mathematical activity in the environment of a visual interactive novel for control.

Level VII. Individual consultation of each student based on the results of the quest. If necessary, the subsequent passage of the story with mathematical content.

Proposed titles were formulated, plots for interactive novels, focused on the rational use of AXMA Story Maker tools for personalizing teaching mathematics, were designed: "Eastern Horoscope", "Systems of Notation", "Seven Wonders of the World", "Professions of the Future", etc.

The third stage of the research is experimental teaching, the inclusion of a mathematics elective for
Table 1. The normality of pre-score and post-score

\begin{tabular}{lcccc}
\hline & \multicolumn{2}{c}{ Pre-score } & \multicolumn{2}{c}{ Post-Score } \\
\hline & Control & Experimental & Control & Experimental \\
\hline Skewness & 0.430 & 0.642 & 0.546 & 0.176 \\
Std. Error & 0.306 & 0.309 & 0.306 & 0.309 \\
z-value & 1.405 & 2.078 & 1.784 & 0.570 \\
Kurtosis & -0.403 & 0.556 & -0.624 & -0.696 \\
Std. Error & 0.604 & 0.608 & 0.604 & 0.608 \\
z-value & 0.667 & 0.914 & 1.033 & 1.145 \\
\hline
\end{tabular}

purposeful work with the means of interactive novels in the curriculum.

\section{Data Analysis}

Before inferential statistical, we determine whether pre-score and post-score have normal distribution. To check normality, we use skewness and kurtosis z-value (Table 1).

For medium-sized samples $(50<\mathrm{n}<300)$, absolute $\mathrm{z}$ value should be smaller than 3.29 for normality (Kim, 2013). So that Pre-score and Post-score measurements have normal distribution at both groups. We prefer ANCOVA from the parametric test to check the hypothesis. ANCOVA model, group and gender is accepted as independent variables and pre-score measurement is accepted covariance variables. To perform statistically analyses, we use free open-source statistics software JASP (JASP, 2021).

\section{RESULTS}

\section{The Main Provisions of the Methodology}

Personalized education in the presented study is considered as an educational approach using individual educational trajectories. It is the approach, according to the results of which the level of individual motivation increases, cognitive interests are satisfied, and the professional self-determination of each student is supported.

The author's understanding of the meaning of "personalized learning" assumes that the student gets the opportunity to choose: the content (from the proposed); the speed, and in some cases the place of training, and the format of the assignments; the method of designing and implementing the educational process; the self-realization mechanism; the form of organization of the learning process.

An interactive novel is a story, the artistic image and content of which are realized with the help of a computer program. The Interactive novel is both a learning tool and an interactive game genre. It tells a story that appears on the screen in the form of text, video, sometimes with background music.

Visual interactive novel is an interactive learning tool. It is a story. The artistic image and content of the novel may vary depending on the student's actions. The 
use of software services for the implementation of interactive novels creates additional conditions in order to form in students the style of thinking that is in demand in society. This style of thinking involves the search for various ways to achieve the goal and understanding the laws of chance. The effectiveness of the organization of the corresponding mathematical activity is determined by the capabilities and skills of the mentor in the digital school.

The use of the developed learning model in the experimental group was aimed at forming a set of educational results in mathematics:

- subject (arithmetic and logical operations, rounding and use of alphabetic syFmbols, construction of graphs of functions and tables, use of scientific mathematical terminology, etc.);

- metasubject (universal principles and patterns, tools for modeling phenomena and processes; understanding the areas of application of mathematical knowledge and skills in the digital society; simple and complex conditions; working with a problem formulation; search, presentation and storage of information; inductive and deductive ways of reasoning; algorithmic nature of activities in the interactive environment, etc.);

- personal (formation of the sense of responsibility to other users for reliability of information; development of critical thinking and creative abilities of students when analyzing and making generalizations of information in the course of solving problems; support for independent choice in the interactive environment; use of digital resources for the implementation of educational and cognitive goals and self-development, etc.);

So, to achieve the aim of the research, the personalized model of teaching mathematics was developed, the components of which are: the interactive novel (plot for presenting a sequence of mathematical facts), the software tool (AXMA Story Maker application); game elements (levels, process visualization tools, characters), didactic principles of teaching mathematics (individualization, accessibility, consistency, etc.).

The personalized model of teaching mathematics by means of interactive novel is divided into the following levels:

Level 1. "Personalization for learners". By means of interactive novels in the experimental group the teacher creates conditions and opportunities for acquiring new mathematical knowledge and skills. In the designed conditions and in the process of interactive interaction with the software environment students make their own choice, observe the reaction of the environment, receive either confirmation of their hypothesis or return to the previous fragment of the novel.
Level 2. "Personalization by efforts of the student". In the interactive visual environment when studying mathematical patterns, ideas and approaches, a member of the experimental group receives new tools, algorithms, methods in order to personalize own subsequent learning.

It should be noted that in the developed personalized model of teaching mathematics, the rate of presentation of a new fragment of the novel is also designed taking into account the individual characteristics and capabilities of the experimental group participants.

Another important circumstance is that for the experimental group work with fragments of the visual novel in the interactive environment presupposes obtaining fundamental theoretical knowledge while playing. By including game elements, not only the presentation of the educational material is changed, but when solving mathematical problems positive emotional background is maintained and stress factors are minimized.

The author's conclusions of the presented work confirm the previously obtained information by Soboleva et al. (2018) on the effectiveness of the use of interactive technologies when teaching mathematics.

The advantages of the AXMA Story Maker software include the following:

free version allows to create game applications, tests, interactive novels, quests;

- structure of links between paragraphs is displayed on the main screen. The user can adjust the workspace to suit own characteristics of information perception;

- official website has a guide for authors, a blog and other teaching materials to help the developer;

- finished resource can be saved and used as an html file;

- no specialized programming skills are required;

- possibility to work without Internet access.

The AXMA Story Maker application integrates the capabilities of the JavaScript language. Figure 1 shows the workspace and tools for making a publication. When adding text, one can work with color, font and format; there are tags for designing paragraphs and links; there is a possibility to add buttons and audio files; there are functions for copying, scaling, etc. Thus, when developing and filling a novel, the mentor of the digital school is required to have basic skills and information literacy.

Thus, the use of AXMA Story Maker made it possible to use text information, graphics, and sound when designing interactive visual novels.

All of the above, firstly, corresponds to the age and psychological characteristics of the thinking of modern adolescents; secondly, it organically complements the rigor of mathematical theories. 


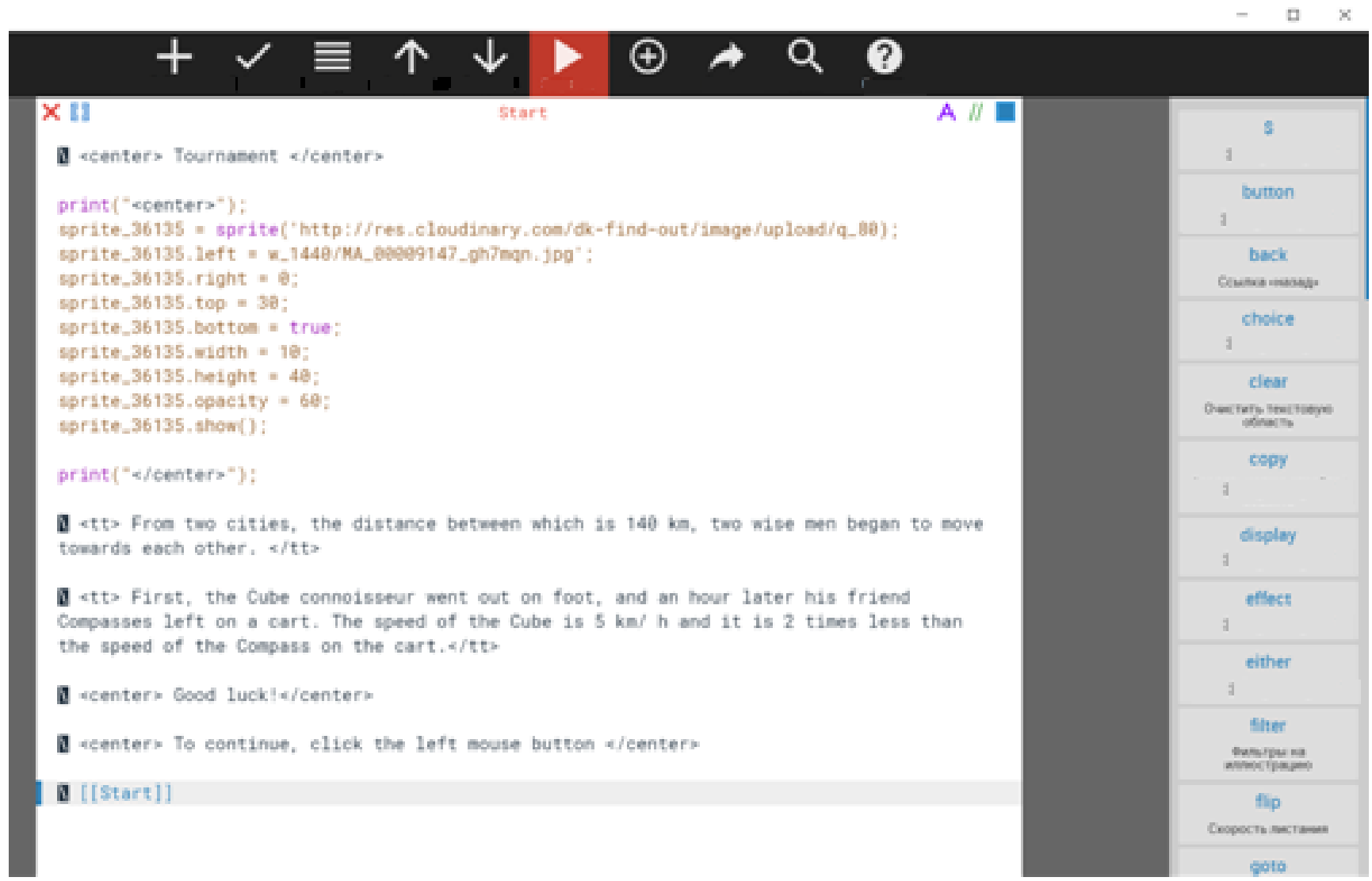

Figure 1. Workspace and tools for making a publication

\section{Educational and Cognitive Activity of Students in the Visual Interactive Novel Environment}

Visual novels include two main elements: visual (static pictures) and literary (the text of the story itself).

With the help of interactive novels the personalized learning model was designed and implemented, it is focused on a qualitative change in the level of academic achievements of schoolchildren. The entire story is divided into publications - images of the working field, which combine various forms of information presentation (text, graphics, sound). Each publication is a separate element of the learning model. Movement through the plot of the story, movement of the character through publications is determined by the choice of the student. The content of the publications is mathematical theory, practice-oriented tasks and exercises.

The meaningful elements in the developed educational model in mathematics for students of the experimental group are: the concept of the formula, the arithmetic expression, the equation/inequality, the roots of the equation, etc. It should be noted that the study of each topic in the experimental group is designed for several classes (mastering new material, developing mathematical skills when working with publications of the visual novel, doing control tasks in the interactive environment).

In the experimental group the primary focus was precisely on the acquisition of new theoretical knowledge, its meaningful application when solving mathematical problems. To involve students in complex intellectual activities (due to the need to memorize, formulate, generalize, check, etc.), rigorous mathematical calculations, the means of interactive stories were used. Introduction to the independence, cognitive activity, argumentation and responsibility for decision-making took place through the nonlinear space of the game world. The means of interactive novels were used to involve students in complex intellectual activities (due to the need to memorize, formulate, generalize, check, etc.) and rigorous mathematical calculations.

As an example, let us consider one of the interactive visual novels in AXMA Story Maker, which supports mathematics learning in the personalized model for the experimental group.

Once the Lord of the country $X$ decided to choose his successor among all the wise men, scientists of the kingdom of Oz. He invited them to his place under the pretext of participating in the tournament "What? Where? When?" It was winter time and there were severe frosts. To get to the site of the tournament travelers had to go through a forest, a valley, a ravine, unfriendly giants, a lake, a swamp, and abandoned villages. 
Let us describe some of the features of the presentation of mathematical material in publications of the interactive novel.

All guests independently chose their paths and means of transportation. So, one of the publications of the novel contained the following task as an alternative: from two cities, the distance between which is $140 \mathrm{~km}$, two wise men began to move towards each other. At first, the expert Cube came out on foot and an hour later his friend Compass left by carriage. The speed of Cube is $5 \mathrm{~km} / \mathrm{h}$ and it is 2 times less than the speed of Compass who goes by carriage.

The essence of math activity: make an equation and determine the time before friends' meeting. Working with the interactive environment assumes that from the proposed options the student must choose the answer that he/she considers correct. Then the student clicks on this answer with the left mouse button and goes to the next publication.

\section{[[ ${ }^{*} 10$ hours | Cube and Compass]] \\ [[15 hours | error Cube's way]] \\ [[1 hours | error Compass's way]]}

The choice of "Error Cube's way" assumed the execution of an additional task for drawing up an equation, expression of one variable through another, etc.

For example, it involved the following task: "To find which way the expert traveled one should find the product of speed and time spent during travel. It is known that the carriage moved at a speed of $10 \mathrm{~km} / \mathrm{h}$ and the whole journey took 5 hours. Accordingly, Cube overcame "...." km "? From the proposed options, one needs to choose the correct answer and click on this answer with the left mouse button:

[[*50 km | Cube and Compass]]

[[50 km/h | error Cube's way]]

[[2 km | error Compass's way

At the same time, the choice "Cube and Compass" corresponded to the continuation of the novel. For example, go to the next publication: "On the way Cube met his old friend Compass, who was crossing the valley alone. Cube invited him to his carriage, since it would be more fun for the two of them to get there. Compass agreed, and they went to the Lord of the country $X$ together".

Thus, the students in the experimental group received in each subsequent publication either a refinement of the mathematical theory or new mathematical tasks. Next publication is a free choice of each student.

During the implementation factors corresponding to the specifics of mathematics education, didactic principles, mechanics of interactive novels and quests were taken into account:
- information presented in each of the paragraphs is concise and structured;

- base on interdisciplinary and interdisciplinary relationships ;

- tasks and questions for the novel are designed in accordance with the current educational standards and curricula;

- text component is checked for the presence/absence of errors;

- only generally accepted mathematical terms and notations are used.

An important result of the study is the definition of groups of exercises for an interactive novel that work as efficiently as possible to achieve the required personality qualities and the level of mathematical preparation:

Group 1. Exercises for the formation of skills. According to the method of execution, they are divided into:

a) imitative, for example, "Confirm if this is the case";

b) wildcards. There is a substitution of mathematical data, values in a formula, expression. For example: "Object if this is not the case";

c) transformational. They are expressed in changing the order of mathematical actions, operations and variables, etc., for example: "If you agree, confirm, but write down your version";

d) reproductive. Assume playback, for example, "Guess!".

Group 2. Exercises for the development of skills: write down what you have heard or read in a mathematical / logical expression; express your own attitude to a mathematical fact, a mathematical event.

Thus, the students in the experimental group received in each subsequent publication either a refinement of the mathematical theory or new mathematical tasks. The transition to publication is a free choice of the student himself. The students in the control group worked at the elective using the educationalmethodological complex of Makarchev et al. This teaching material is focused on updating knowledge, as well as preparing for the study of courses in geometry, physics, chemistry and geography in subsequent classes. The complex is included in the federal list of textbooks. The educational-methodological complex uses a differentiated decoration for various sections: theoretical information, tasks for working in pairs and for revising, entertaining facts on the history of the development of mathematics, etc.

Also, at the elective the participants of the control group used workbooks and training programs, they participated in mathematical dictations. The classes in the control group were organized according to the principle "from theory to practice".

When developing the interactive novel with mathematical content, additional opportunities were 
also created for the development of teamwork skills, cross-industry communication, and the propaedeutics of working with technical documentation was carried out.

There is on fact that is of particular importance for solving future professional tasks when implementing innovations, the fact is that the concretization of the content of each educational game space with mathematical content does not occur at the initiative of the mentor, which is typical to the traditional system of teaching mathematics. The direction for mathematical research is determined by the students themselves.

\section{Experimental Evaluation}

\section{The ascertaining stage of the experiment}

At the first stage of the experiment, materials of specially organized testing were used to assess the input conditions, the test took into account the priorities of the digital society, the competence of the atlas of new professions. All questions and tasks were developed by the authors in accordance with the requirements of state federal educational standards. Schoolchildren were asked to solve five tasks.

The solution to the first problem is associated with the development of logical thinking. For example, schoolchildren are given cards with a sequence of numbers in a specific order. They need to continue the pattern and determine the number that should be on the blank card.

The solution to the second problem involves calculating the value of a mathematical expression. For example, it is to determine the value of the expression $\mathrm{F}$ $=\mathrm{m}^{*} \mathrm{a}$ if the mass and acceleration are known.

For the correct solution of each of these problems, the pupil received 1 point.

When solving the third task, the schoolchild had to choose from the proposed formulations of problems the one which conditions correspond to a certain mathematical equation. For example, $33 /(x+6.5)+4 /$ $(x-6.5)=1$. For the correct solution of the problem of this level, the student received 2 points. Examples of tasks:

1. The yacht "Pobeda" sailed $4 \mathrm{~km}$ upstream of the river, and then another $33 \mathrm{~km}$ downstream. Captain Wrangel calculated that they spent one hour on the whole journey. Find the speed of the yacht if the river speed is $6.5 \mathrm{~km} / \mathrm{h}$.

2. From the diaries of a young traveler "Today we examined the atolls of the islands. At the same time, our expedition covered $4 \mathrm{~km}$ on foot, $33 \mathrm{~km}$ we sailed on the ship "Victoria" along the equator forward and $6.5 \mathrm{~km}$ when returning back". Help determine the speed of travelers.

To solve the fourth problem, the schoolchild had to compose an equation on his/her own. For example, a cruise ship covered $108 \mathrm{~km}$ downstream and $84 \mathrm{~km}$ upstream, spending 8 hours for the entire journey. It is known that the speed of the river is $3 \mathrm{~km} / \mathrm{h}$. Find own speed of the cruise ship. Having designated the own speed of the cruise ship as $x \mathrm{~km} / \mathrm{h}$, write an equation that corresponds to the condition of the problem.

For the correct solution of the problem of this level, the schoolchild received 3 points.

The fifth task involved the use of software and information technology. For the correct solution 5 points were given.

For example, Hermione decided to organize a picnic for her friends. To do this, she compiled a "memo", where she wrote down all the purchases necessary for a good rest (food, dishes, their quantity, etc.). Hermione, like a real researcher, approached the task in a complex way: the girl studied all the prices in magic stores and shops. For structuring she compiled a spreadsheet with a price range for each item. Determine in which shop Hermione's costs will be minimal.

For example, Hermione decided to organize a picnic for her friends. To do this, she compiled a "memo", where she wrote down all the purchases necessary for a good rest (food, dishes, their quantity, etc.). Hermione, like a real researcher, approached the task in a complex way: the girl studied all the prices in magic stores and shops. For structuring she compiled a spreadsheet with a price range for each item. Determine in which shop Hermione's spend will be minimal.

So, for the correct solution of the control tasks, the schoolchild could receive the maximum of 12 points. The work was considered completed (mark "credit") if the schoolchild scored more than 7 points.

Thus, it was possible to collect data on 121 schoolchildren, of whom the experimental (60 students) and control (61 schoolchild) groups were formed. The sample was not random. The average age of the respondents was 13 . In the experimental group there were $51 \%$ of girls and $49 \%$ of boys.

\section{Forming stage of the experiment}

The training in the control group was conducted according to the traditional methodology, without special organization of activities in the environment of interactive novels and quests. They were active and independent in research. The classes were organized in the form of practical work on solving mathematical plot problems. Exercises on separate topics were used. The training of schoolchildren from the experimental group took place according to the described variant.

At the forming stage of the experiment the teacher analyzed the requirements of the digital economy to the quality and level of mathematical training of graduates. The provisions of the current state federal educational standards determine that as part of mathematics education the student must acquire a certain amount of 
Table 2. The results of the test

\begin{tabular}{lcccc} 
& \multicolumn{2}{c}{ Before the experiment } & \multicolumn{2}{c}{ After the experiment } \\
\cline { 2 - 5 } & $\begin{array}{c}\text { Experimental group } \\
\text { (60 students) }\end{array}$ & $\begin{array}{c}\text { Control group } \\
(61 \text { students) }\end{array}$ & $\begin{array}{c}\text { Experimental group } \\
\text { (60 students) }\end{array}$ & $\begin{array}{c}\text { Control group } \\
(61 \text { students) }\end{array}$ \\
\hline $\begin{array}{l}\text { Percentage of students who } \\
\text { received the mark "no credit" }\end{array}$ & $56.7 \%(34)$ & $55.7 \%(34)$ & $15 \%(15)$ & $50.8 \%(31)$ \\
$\begin{array}{l}\text { Percentage of students who } \\
\text { received the mark "credit" }\end{array}$ & $43.3 \%(26)$ & $44.3 \%(27)$ & $75 \%(45)$ & $49.2 \%(30)$ \\
\hline
\end{tabular}

fundamental mathematical knowledge, master the mathematical methods of cognition and the general culture of the nation. In addition, teaching mathematics should perform developmental functions: to form intellectual skills necessary for any person regardless of what field of activity he/she will be engaged in in the future.

Classes for students in the control group were conducted according to the traditional method of teaching mathematics, without special organization of activities in the environment of interactive short stories and quests. They were active and independent in research, which was organized in the form of practical work on solving mathematical story problems, performing exercises on specific topics. Schoolchildren from the experimental group were taught according to the described way.

The second stage of the study was devoted to correlating the topics of the course "Entertaining mathematics" (elements of logic, formulas, equations, inequalities, motion problems, percentage problems, etc.) with the capabilities of the software tool for creating interactive short stories. In particular, the sequence of classes was determined.

Acquaintance with AXMA Story Maker, basic commands and user interface icons.

Work with forms and text wondows, moving through the branches and levels of the interactive short story.

Execution of a demo version of the interactive short story to study or consolidate theoretical material.

Passing the test version of the interactive short story.

Approximate titles were formulated, plots for interactive short stories, focused on the rational use of AXMA Story Maker tools for personalizing teaching mathematics, were designed: "Eastern Horoscope", "Systems of Notation", "Seven Wonders of the World", "Professions of the Future", etc.

At the fixing stage of the experiment, control testing was also carried out. The types of tasks and principles of assessment corresponded to the tasks and the procedure of the entry test. Information about the measurement results before and after the experiment is presented in Table 2.

Doing the quantitative analysis of the obtained results, we conclude that $75 \%$ of the students in the
Table 3. Descriptive statistics for control and experimental groups

\begin{tabular}{lcccc}
\hline & \multicolumn{2}{c}{ Pre-Score } & \multicolumn{2}{c}{ Post-Score } \\
\hline $\mathrm{N}$ & Cont. & Exp. & Cont. & Exp. \\
Mean & 61 & 60 & 61 & 60 \\
Std. Dev. & 6.574 & 6.233 & 7.016 & 7.367 \\
Minimum & 2.210 & 1.691 & 2.102 & 1.877 \\
Maximum & 2.000 & 3.000 & 4.000 & 4.000 \\
\hline
\end{tabular}

experimental group successfully coped with the control tasks. According to the results of input measurements, this value was equal to $43.3 \%$. The number of students who did not complete the task decreased from $56.7 \%$ to $15 \%$. The dynamics of the results in the control group is not so significant. $49.2 \%$ of schoolchildren received the mark "credit". Initially, this figure was $44.3 \%$. The number of students who could not complete the final test was $50.8 \%$ (compared to $55.7 \%$ after the entry test).

In general, the pedagogical experiment allows to conclude that teaching mathematics according to the designed personalized model based on visual novels contributes to improving the quality of education.

The level of academic results in mathematics in the experimental group became significantly higher due to the fact that the information environment for studying the topics of the course "Entertaining mathematics", supported by interactive means, made it possible to create and provide conditions for:

- taking into account the individual, age and psychological and physical characteristics of students;

- studying universal methods, approaches that are the basis of research, educational and cognitive and further professional activities of schoolchildren;

- developing the skills of independence in decisionmaking, responsibility for one's choice and its consequences;

- self-education;

- creating situations of success;

- organization of creative activity.

\section{Control stage of the experiment}

The pre-scores of the experimental and control groups are close to each other but there is a difference in the post-scores (Table 3). To test this differentiation statistically, the following Ho hypothesis was written. 
Table 4. ANCOVA results

\begin{tabular}{|c|c|c|c|c|c|c|}
\hline Cases & Sum of Squares & $\mathrm{df}$ & Mean Square & $\mathrm{F}$ & $\mathrm{p}$ & $\eta^{2} p$ \\
\hline Group & 11.734 & 1 & 11.734 & 7.941 & 0.006 & 0.064 \\
\hline Gender & 4.231 & 1 & 4.231 & 2.863 & 0.093 & 0.024 \\
\hline Group * Gender & 0.258 & 1 & 0.258 & 0.175 & 0.677 & 0.002 \\
\hline Pre-score & 293.784 & 1 & 293.784 & 198.825 & $<.001$ & 0.632 \\
\hline Residuals & 171.402 & 116 & 1.478 & & & \\
\hline
\end{tabular}
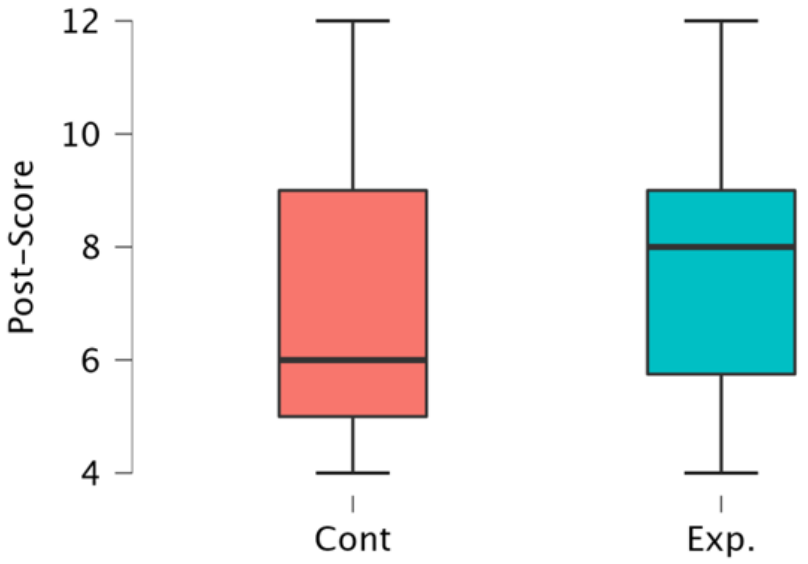

Group

Figure 2. Box plot post-score of control and experimental groups

$\mathrm{H}_{0}$-The mean of the experimental group post-score is statistically equal to the mean of the control group post-score.

Although there was minimal difference between the experimental and control groups' pre-scores, the ANCOVA test was used to compare the groups' postscores.

The difference in post-scores is statistically significant level to groups $(\mathrm{p}<0.05)$. According to partial eta square (0.064), the effect size is moderate level (Rienties \& Tempelaar, 2013). But there is no gender's effect on the post-score $(p>0.05)$ and also gender and group together effect is not statistically significant ( $p>0.05)$.

When Table 4 and Figure 2 are evaluated together, the post-score of the experimental group is statistically higher than the control group. As a result, the Ho "The mean of the experimental group post-score is statistically equal to the mean of the control group post-score." hypothesis was rejected.

Thus, the shift towards improving the quality of educational results in mathematics of students of the experimental group can be considered not accidental.

\section{DISCUSSIONS}

The sample of students was not probabilistic, since the experimental and control groups were formed in such a way as to guarantee the presence in each group of the same skills and personality traits, their identical distribution. For diagnostics, the results of the input control testing were taken into account. Throughout the experiment, creative activity in the interactive environment was carried out by the same teacher, on the same software equipment in special classrooms.

In the environment of the developed interactive novel, mathematical educational results are formed as follows:

1) studying the materials of the interactive novel about the Olympic Games, records and athletes contributes to immersion in the history of the country and sports;

2) manipulating images, audio and video materials from the sphere of art; acquaintance with biographies of scientific figures contributes to aesthetic and spiritual and moral education;

3) when studying new mathematical theory, spelling of complex formulas students show perseverance, determination, diligence, etc.;

4) mathematical education is supported by interactive web quest tasks, during which students work with information on the history, traditions, customs;

5) virtual travel through nature reserves, national parks contributes to the formation of ecological culture. Computer simulations orient students to preserve the natural resources of the planet;

6) the problematic approach to learning maths in the novel's environment is aimed at developing a value attitude to scientific knowledge, creativity and transformative activity (working with puzzles, studying production technology, etc.).

The quality of teaching mathematics also increased due to the fact that both auditory and visual channels of information perception were involved. In the proposed recommendations, we consider it necessary to note the sanitary and hygienic aspect of the use of interactive stories and quests in teaching. So the duration of using the resource in a basic school lesson should not exceed 30 minutes.

When studying the topics of the course "Entertaining Mathematics" in the AXMA Story Maker environment, students learn mathematical facts, theories, methods more consciously, they actively apply them to solve practice-oriented problems; a stable favorable emotional background is created; thought processes (memory, imagination, attention) develop more intensively. The choice of this particular software product made it possible to design the personalized environment that supports the study of basic mathematical concepts, forms demanded mathematical skills, demonstrates the 
capabilities of new interactive tools and game applications, and provides an experience of independent choice in decision-making.

The results of the study are consistent with the conclusions of Jorge and Paredes (2018) about the didactic potential of interactive tools with functionality for designing a nonlinear trajectory of cognition.

The implementation of the formulated recommendations will allow the teacher of the digital school to create additional conditions for personalization of teaching mathematics. Using AXMA Story Maker to develop the interactive novels with math content aligns with digital priorities and convincingly demonstrates the didactic potential of technology to improve the quality of maths education.

\section{CONCLUSION}

The study presents a solution to the problem caused by the need to resolve the contradiction between the requirements of the modern economy for the quality of mathematics training of future specialists and an insufficiently developed methodological base for training graduates that meets these requirements. It was assumed and experimentally proved that acquiring high-quality mathematics education by graduates of the modern school is facilitated by work in the specially designed personalized learning environment based on interactive technologies.

The following features of the development of the personalized learning model by means of interactive novels were noted, they maximally contribute to improving the quality of educational results in mathematics:

1. Correlation of the educational goal (in this case) and the results of educational and search activities in the environment of the interactive novel. First of all, before using a game application that supports interactivity of interaction and the nonlinear personal trajectory of cognition, it is necessary to determine the goals and intended results (personal, subject, metasubject): learners must remember mathematical facts, get logical conclusions, choose a reasoned answer, build their personal educational route from "ignorance to knowledge". The goal will determine not only the content of the visual novel, but also the number of required publications, plot, and levels of material presentation.

2. Understanding and taking into account the individual, age and psychological and physical characteristics of students.

3. Determination of the place and significance of the interactive novel for the main course in mathematics: where and when the resource will be used, the duration of the work.

4. Designing the plot of the interactive novel. The plot for the space of the game (as in the described option) can go beyond the limits of the studied discipline. The plot of the novel can be based on a literary work, film events, historical or geographical discovery.

5. The choice of the text component, i.e. features of drawing up the system of tasks and questions. We advise to adhere to the following recommendations: order tasks and questions by level of difficulty; the first problem (the starting point of the novel) is the simplest, containing only known mathematical facts and firmly mastered formulas; the wording should be understandable for students, consistent with their cognitive interests and level of academic achievement.

6. Development of the personalized educational trajectory. When solving each of the problems, the student must be offered a choice of one of several answer options. To do this, the teacher needs to think over the following in the interactive novel:

- what will happen if the student answers the question correctly, and to which publication he/she will move;

- what will happen if the student makes a mistake, and what mathematical theory (volume, degree of detail) will allow him/her to understand and correct it.

The personalized model of teaching mathematics, developed by means of interactive novels, contributes not only to improving the quality of the obtained subject and educational knowledge, but also contributes to the development of thinking. In the course of educational and cognitive activities in AXMA Story Maker, in the process of making a decision and making an independent choice, soft skills that are in demand by the digital society are formed: planning, search, critical assessment and processing information, the ability to work in an uncertain future, responsibility.

Thus, the use of interactive novels as the basis for the personalized model of teaching mathematics contributes to an increase in the level of academic achievements of schoolchildren. Research materials can be used to develop ideas for personalizing learning in the digital school.

Author contributions: All authors have sufficiently contributed to the study, and agreed with the results and conclusions.

Funding: This paper has been supported by the Kazan Federal University Strategic Academic Leadership Program.

Declaration of interest: No conflict of interest is declared by authors.

\section{REFERENCES}

Alexandrov, D., Ivaniushina, V., \& Simanovsky, D. (2017). Online educational resources for schoolchildren and the digital divide. Voprosy Obrazovaniya / Educational Studies Moscow, 3, 183201. https:// doi.org/10.17323/1814-9545-2017-3183-201

Alfaro-Arce, A. L., \& Alpízar-Vargas, M. (2019). College education of elementary school teachers: The case 
of mathematics. [La formación universitaria de docentes de educación primaria: El caso de matemáticas]. Uniciencia, 33(2), 110-154. https://doi.org/10.15359/ru.33-2.8

Bawa, S. K., Kaushal, R., \& Dhillon, J. K. (2020). Unification of multimedia with techniques of art and vedic aphorisms for development of mathematical skills: A study of Indian and UK school students. Journal on Efficiency and Responsibility in Education and Science, 13(3), 130139. https:// doi.org/10.7160/eriesj.2020.130303

Bovermann, K., \& Bastiaens, T. J. (2020). Towards a motivational design? Connecting gamification user types and online learning activities. Research and Practice in Technology Enhanced Learning, 15(1), 4-18. https: / / doi.org/10.1186/s41039-019-0121-4

Catarino, P., Vasco, P., Lopes, J., Silva, H., \& Morais, E. (2019). Aprendizaje cooperativo para promover el pensamiento creativo y la creatividad matemática en la educación superior [Cooperative learning on promoting creative thinking and mathematical creativity in higher education]. REICE. Revista Iberoamericana Sobre Calidad, Eficacia y Cambio En Educacion, 17(3), 5-22. https://doi.org/10.15366/ reice2019.17.3.001

Chernyaeva, N. V. (2020). Problem of personalization of learning abroad. Pedagogical Education in Russia, 2, 36-40. https:/ / doi.org/10.26170/ po20-02-05

del Río, L. S., Sanz, C. V., \& Búcari, N. D. (2019). Incidence of a hypermedia educational material on the teaching and learning of mathematics. Journal of New Approaches in Educational Research, 8(1), 50-57. https:/ / doi.org/10.7821/naer.2019.1.334

Galimova, E., Konysheva, A., Kalugina, O., \& Sizova, Z. (2019). Digital educational footprint as a way to evaluate the results of students' learning and cognitive activity in the process of teaching mathematics. Eurasia Journal of Mathematics, Science and Technology Education, 15(8), em1732. https:/ / doi.org/10.29333/ ejmste/108435

Gault, F. (2019). User innovation in the digital economy. Foresight and STI Governance, 13(3), 6-12. https: / / doi.org/10.17323/2500-2597.2019.3.6.12

Ghazali, E. M., Mutum, D. S., \& Woon, M. Y. (2019). Multiple sequential mediation in an extended uses and gratifications model of augmented reality game Pokémon Go. Internet Research, 29(3), 504-528. https: / / doi.org/10.1108/IntR-12-2017-0505

Hamada, M. \& Hasan, M. (2017). An interactive learning environment for information and communication theory. Eurasia Journal of Mathematics, Science and Technology Education, 13(1), 35-59. https:/ / doi.org/ 10.12973/eurasia.2017.00603a

Harding, J. F., Connors, M. C., Krauss, A. F., Aikens, N., Malone, L., \& Tarullo, L. (2019). Head start teachers' professional development, well-being, attitudes, and practices: Understanding changes over time and predictive associations. American Journal of Community Psychology, 63(3-4), 324-337. https:/ / doi.org/10.1002/ajcp.12327

Hillmayr, D., Ziernwald, L., Reinhold, F., Hofer, S. I., \& Reiss, K. M. (2020). The potential of digital tools to enhance mathematics and science learning in secondary schools: A context-specific metaanalysis. Computers and Education, 153, 103897. https:/ / doi.org/10.1016/j.compedu.2020.103897

Hiranyachattada, T., \& Kusirirat, K. (2020). Using mobile augmented reality to enhancing students' conceptual understanding of physically-based rendering in 3D animation. European Journal of Science and Mathematics Education, 8(1), 1-5. https://doi.org/10.30935/scimath/9542

Insorio, A. O., \& Librada, A. R. P. (2021). Enhancing mathematical critical thinking and problemsolving skills through Emergenetics ${ }^{\circledR}$ as a grouping mechanism. Contemporary Mathematics and Science Education, 2(1), ep21002. https://doi.org/10.30935 /conmaths/9289

Isaeva, Z. I. (2019). Application of interactive teaching methods at mathematics lessons. Problems of Modern Pedagogical Education, 63(4), 81-84.

Isupova, N. I., \& Suvorova, T. N. (2018). Text maze as a tool for gamification of the learning process. Informatics at school, 2, 41-46.

JASP (Version 0.16). (2021). https:/ /jasp-stats.org/

Jorge, J., \& Paredes, R. (2018). Passive-aggressive online learning with nonlinear embeddings. Pattern Recognition, 79, 279-289. https://doi.org/10.1016/ j.patcog.2018.01.019

Karakozov, S. D. \& Ryzhova, N. I. (2019). Information and education systems in the context of digitalization of education. Journal of Siberian Federal University, 12(9), 1635-1647. https:/ / doi.org /10.17516/1997-1370-0485

Karavaev, N. L., \& Soboleva, E. V. (2017). Analysis of software services and platforms that have the potential to gamify learning. Scientific and Methodological Electronic Journal "Concept", 8, 170202.

http:/ / doi.org/10.24422/mcito.2017.8.6960

Kaya, M. H., \& Adiguzel, T. (2021). Technology integration through evidence-based multimodal reflective professional training. Contemporary Educational Technology, 13(4), ep323. https:/ / doi.org/10.30935/cedtech/11143

Kim, H.-Y. (2013). Statistical notes for clinical researchers: assessing normal distribution (2) using skewness and kurtosis. Restorative Dentistry $\mathcal{E}$ Endodontics, 38(1), 52. 
Kotyurgina, A. S., Fedorova, E. I., Nikolaev V. B., \& Nikitin, Y. B. (2020). Evolution of USE and its impact on the mathematical training of schoolchildren. Education and Science, 22(5), 9-36. http:/ / doi.org/10.17853/1994-5639-2020-5-9-36

Lai, Y.-H. (2019). The application of meta-analytic SEM on exploring factors that influence teachers' usage of interactive whiteboard. Pedagogical Research, 4(3), em0038. https:/ / doi.org/10.29333/pr/5854

Legaki, N., Xi, N., Hamari, J., Karpouzis, K., \& Assimakopoulos, V. (2020). The effect of challengebased gamification on learning: An experiment in the context of statistics education. International Journal of Human Computer Studies, 144, 102496. https://doi.org/10.1016/j.ijhcs.2020.102496

Levchenko, E. A., \& Mantorova, A. (2020). Specificity of post-apocalyptic imagery in the space of the visual novel "Getting Through". The world of science and art: collection of articles on the materials of the Regional scientific-practical conference of students, graduate students and young scientists, Perm State University, 1, 243-252.

Lyubimov, L. L. (2020). Concept of modernization of general education. Without slogans, appeals and admonitions, but with answers to questions: What needs to be done? Why should it be done? How can it be done? National Research University Higher School of Economics.

Mora-Luis, C. E., \& Martin-Gutierrez, J. (2020). The Change of Educational Processes, Learning and Teaching in Engineering Education. Eurasia Journal of Mathematics, Science and Technology Education, 16(3), em1828. https://doi.org/10.29333/ejmste/ 116034

More, M. (2018). Mathematics and engineering in real life through mathematical competitions. International Journal of Mathematical Education in Science and Technology, 49(2), 305-321. https:/ / doi.org/10.1080/0020739X.2017.1387297

Nikolaeva, E. N., \& Egorova, I. P. (2020). Interactive methods of teaching mathematics in technical universities: Educational and educational aspect. Bulletin of Samara State Technical University. Series: Psychological and Pedagogical Sciences, 1(45), 139-151. https:/ / doi.org/10.17673/vsgtu-pps.2020.1.10

Novitasari, M., Sutama, Narimo, S., Fathoni, A., Rahmawati, L., \& Widyasari, C. (2020). Habituation of digital literacy and critical thinking in mathematics in elementary school. International Journal of Scientific and Technology Research, 9(3), 3395-3399.

Olefirenko, N. V., Kostikova, I. I., Ponomarova, N. O., Bilousova, L. I., \& Pikilnyak, A. V. (2019). Elearning resources for successful math teaching to pupils of primary school. CEUR Workshop
Proceedings, 2433, 443-458. http://ceur-ws.org/ Vol-2433/paper30.pdf

Park, J., Bermudez, V., Roberts, R. C., \& Brannon, E. M. (2016). Non-symbolic approximate arithmetic training improves math performance in preschoolers. Journal of Experimental Child Psychology, 152, 278-293. https://doi.org/10.1016/ j.jecp.2016.07.011

Paterson, R. E. (2017). Intuitive cognition and models of human-automaton interaction. Human Factors: The Journal of the Human Factors and Ergonomics Society, 59(1), 101-115. https:/ / doi.org/10.1177/001872081 6659796

Perminov, E. A., Gadjiev, D. D., \& Abdurazakov, M. M. (2019). About relevance of fundamentalisation of mathematical training of students of the pedagogical directions during the digital era. Obrazovanie i Nauka, 21(5), 86-111. https:/ / doi.org/ 10.17853/1994-5639-2019-5-87-112

Ponomarev, A., \& Dezhina, I. (2016). Approaches to the formulation of Russia's technological priorities. Foresight and STI Governance, 10(1), 7-15. https://doi.org/10.17323/1995-459X.2016.1.7.15

Qarkaxhja, Y., Kryukova, N. I., Cherezova, Y. A., Rozhnov, S. N., Khairullina, E. R., \& Bayanova, A. R. (2021). Digital transformation in education: Teacher candidate views on mobile learning. International Journal of Emerging Technologies in Learning, 16(19), 81-93. https://doi.org/10.3991/ ijet.v16i07.21201

Radović, S., Marić, M., \& Passey, D. (2019). Technology enhancing mathematics learning behaviours: Shifting learning goals from "producing the right answer" to "understanding how to address current and future mathematical challenges". Education and Information Technologies, 24(1), 103-126. https:/ / doi.org/10.1007/s10639-018-9763-x

Rienties, B., \& Tempelaar, D. (2013). The role of cultural dimensions of international and Dutch students on academic and social integration and academic performance in the Netherlands. International Journal of Intercultural Relations, 37(2), 188-201. https:/ / doi.org/10.1016/j.ijintrel.2012.11.004

Sabirova, E. G., Fedorova, T. V., \& Sandalova, N. N. (2019). Features and advantages of using websites in teaching mathematics (interactive educational platform UCHI.ru). Eurasia Journal of Mathematics, Science and Technology Education, 15(5), em1729. https:/ / doi.org/10.29333/ ejmste/108367

Savina, N. V. (2020). Methodological foundations of personalization of education. Human Science: Humanities Research, 14(4), 82-90. https:/ / doi.org/ 10.17238/issn1998-5320.2020.14.4.10

Semenykhina O. V., \& Rudenko Y. O. (2018). Problems of educating to programming of students and way 
of their overcoming. Information Technologies and Learning Tools, 66(4), 54-64. http://doi.org/ 10.33407/itlt.v66i4.2149

Shaidullina, A. R., Zakirova, V. G., Kashurnikov, S. N., Arestova, E. N., Shmidt, A. N., \& Kovaleva, N. I. (2018). Students training for innovative entrepreneurial activity: Social responsibility competences. ESPACIOS, 39(02), 15-26.

Smirnov, E. I., Zykova, T. V., \& Tikhomirov, S. A. (2019). The management of school mathematical education with synergistic effect. Perspektioy Nauki $i$ Obrazovania, 37(1), 190-202. https://doi.org/ 10.32744/pse.2019.1.14

Soboleva, E. V., Galimova, E. G., Maydangalieva, Z. A., \& Batchayeva, K. K. (2018). Didactic value of gamification tools for teaching modeling as a method of learning and cognitive activity at school. Eurasia Journal of Mathematics, Science and Technology Education, 14(6), 2427-2444. https://doi.org/10.29333/ ejmste/89843

Soboleva, E. V., \& Perevozchikova, M. S. (2019). Features of training future teachers to develop and use mobile gaming applications with educational content. Perspektivy nauki i obrazovania - Perspectives of Science and Education, 41(5), 428-440. https: / / doi.org/10.32744/pse.2019.5.30

Soboleva, E. V., Suvorova, T. N., Zenkina, S. V., \& Gerasimova, E. K. (2020). The development of critical thinking through the involvement of pupils in competitive robotics (from work experience). Perspektivy nauki $i$ obrazovania - Perspectives of Science and Education, 44(2), 268-284. https:// doi.org/10.32744/pse.2020.2.21

Solodikhina, M. V., \& Solodikhina, A. A. (2019). Development of critical thinking of master's degree students using stem cases. Obrazovanie $i$ Nauka. 21(3), 125-153. https://doi.org/10.17853/19945639-2019-3-125-153

Urvanova, N. A. (2018). Model of development of mathematical thinking of students on the lessons of the disciplines of mathematical and natural science cycle. Innovative Development of Professional Education, 4(20), 39-45.

Vaganova, O. I., Khokhlenkova, L. A., Chelnokova, E. A., \& Aleshugina, E. A. (2020). Methodological aspects of the organization of the learning process using modern interactive didactic means. Baltic Humanitarian Journal, 9(3), 29-33. https:/ / doi.org/10.26140/bgz3-2020-0903-0005

Varshavskaya, E., \& Kotyrlo, E. S. (2019). Graduates in engineering and economics: Between demand and supply. Voprosy Obrazovaniya / Educational Studies Moscow, 2, 98-128. https:/ / doi.org/10.17323/18149545-2019-2-98-128

Yung, O. C., Junaini, S. N., Kamal, A. A., \& Md Ibharim, L. F. (2020). I slash 100\%: Gamification of mathematics with hybrid QR-based card game. Indonesian Journal of Electrical Engineering and Computer Science, 20(3), 1453-1459. https://doi.org /10.11591/ijeecs.v20.i3.pp1453-1459

Záhorec, J., Hašková, A., \& Munk, M. (2010). Impact of electronic teaching materials on process of education results of an experiment. Informatics in Education, 9(2), 261-281. https:/ / doi.org/10.15388/ infedu.2010.19

Zaripova, I. M., Shaidullina, A. R., Upshinskaya, A. E., Sayfutdinova, G. B., \& Drovnikov, A. S. (2014). Modeling of petroleum engineers designtechnological competence forming in physicalmathematical disciplines studying process. American Journal of Applied Sciences, 11(7), 10491053. https:/ / doi.org/10.3844/ajassp.2014.1049.1053

Zeynivandnezhad, F., \& Bates, R. (2018). Explicating mathematical thinking in differential equations using a computer algebra system. International Journal of Mathematical Education in Science and Technology, 49(5), 680-704. https://doi.org/10.1080/0020739X.2017.1409368

\section{https://www.ejmste.com}

